
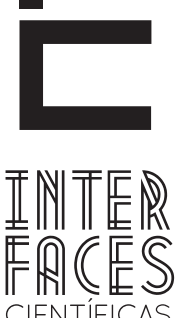

CIENTÍFICAS

HUMANASE SOCIAIS

ISSN IMPRESSO 2316-3348

E-ISSN 2316-3801

DOI - 10.17564/2316-3801.2018v6n3p81-92

\title{
A CIÊNCIA NOS TRIBUNAIS: DECIDINDO SOBRE AÇÕES TECNOCIENTIIFICAS
}

\author{
THE SCIENCE IN COURT: DECIDING ON TECHNOSCIENTIFIC ACTIONS \\ LA CIENCIA EN LA CORTE: DECIDIR SOBRE LAS ACCIONES TECNOCIENTÍFICAS
}

Giselle Marie Krepsky ${ }^{1}$

Thayane Cristine Barreto ${ }^{2}$

\section{RESUMO}

Este artigo trata da possibilidade de abertura cognitiva e aprendizagem do Sistema do Direito ao decidir questões envolvendo ações tecnocientíficas com potencial danoso futuro. Â luz da teoria Sistêmica de Niklas Luhmann, para quem o Sistema Social é composto por vários subsistemas que são fechados operacionalmente, mas abertos cognitivamente, a pesquisa observou a inter-relação entre os Sistemas parciais da Ciência e do Direito com foco na capacidade de aprendizagem do Direito com as comunicações científicas. 0 objetivo da pesquisa foi identificar como o Direito vem decidindo sobre estas temáticas a partir da análise dos julgados dos Tribunais no contexto de hipercomplexidade social que potencializa o risco decisional. Conclui que o Sistema do Direito apresenta dificuldades ao decidir questões referentes às novas tecnologias uma vez que ele não possui na sua estrutura conhecimentos necessários para julgá-las. Isso leva a uma necessária decodificação das comunicações científicas (perícias) as quais norteiam boa parte das decisões. Por outro lado, o Sistema do Direito, embora capaz de assimilar e incorporar a informação científica, dela ainda mantém sua autonomia, mantendo sua autopoise.

\section{PALAVRAS-CHAVE}

Direito. Tecnociência. Aprendizagem Sistêmica. Sociedade Complexa. Danos futuros. 


\section{ABSTRACT}

This article deals of the possibility of opening and cognitive learning of the Law System when deciding issues involving Technoscientific actions with future potential harmful. Under the light of the systemic theory Niklas Luhmann, for whom the social system consists of several subsystems that are closed operationally but open cognitively, the research noted the interrelationship between the partials Science Systems and Law Systems with focus on learning ability of Law with scientific communications. The objective of the research was to identify how the law is deciding on these subjects from the analysis of the judgments of the courts in the context of social hypercomplexity that potentiates the decisional risk. It concludes that the Law Sys- tem presents difficulties when deciding issues related to new technologies since it does not have in its structure knowledge needed to judge them. This leads to a necessary decoding of scientific communication (technical expertise) which guide many of the decisions. On the other hand, the Law System, although able to assimilate and incorporate scientific information, it still retains its autonomy, maintaining its autopoise.

\section{KEYWORDS}

Law. Technoscience. Systemic learning. Society Complex. Future damage.

\section{RESUMEN}

Este artículo trata de la posibilidad de la apertura y del aprendizaje cognitivo del Sistema del Derecho al decidir cuestiones que implican acciones tecnocientíficas con futuro potencial dañino. A la luz de la teoría sistémica de Niklas Luhmann, para quién el sistema social se compone de varios subsistemas que están cerrados operacionalmente pero abierto cognitivamente, la pesquisa observó la interrelación entre los Sistemas parciales de la Ciencia y del Derecho con énfasis en la capacidad de aprendizaje del Derecho con las comunicaciones científicas. El objetivo de la investigación fue identificar cómo el Derecho está decidiendo sobre estos temas a partir del análisis de las decisiones judiciales en el contexto de hipercomplejidad social que potencia el riesgo de toma de decisiones. Se llega a la conclu- sión de que el sistema del Derecho presenta dificultades a la hora de decidir cuestiones relacionadas con las nuevas tecnologías, ya que no tiene en su estructura conocimiento para juzgarlos. Esto conduce a una decodificación necesaria de la comunicación científica (conocimientos técnicos) que orientan muchas de las decisiones. Por otro lado, el sistema del Derecho, aunque es capaz de asimilar e incorporar la información científica, mantiene su autonomía y su autopoiesis.

\section{PALABRASCLAVE}

Derecho. Tecnociencia. Aprendizaje sistémica. Sociedad compleja. daños futuros. 


\section{INTRODUÇ̃̃O}

Os avanços progressivos da tecnologia podem proporcionar riscos à sociedade haja vista a sua imprevisibilidade, uma vez que o ser humano não possui, atualmente, conhecimentos conclusivos sobre tudo o que transforma com a técnica. Tais modificações posicionam a sociedade em um paradoxo posto que, ao mesmo tempo em que estas evoluções podem auxiliar na melhoria da vida humana têm potencial para causar efeitos devastadores à sociedade, incluindo seu ambiente. Há uma constante complexificação social.

Nesse contexto Luhmann (1998, p. 48) ressalta que: "Complejidad [...] significa coaccíon a seleccionar. Coaccíon a seleccionar significa contingencia, y contingencia significa riesgo". Assim, com o constante avanço científico a relação entre o Direito e a Ciência se estreita. Isto porque, por um lado a Ciência possui a função de construir e comunicar conhecimento com base na sua própria estrutura que é voltada preponderantemente para a cognição e a aprendizagem, respeitando seu código: verdade/não verdade sobre as coisas.

Por outro lado, o Direito é encarregado de estabilizar as expectativas sociais a partir da aplicação do que é positivado pelo Sistema da Política (legislativo) e para o qual também são delegadas responsabilidades de permissão e impedimento de ações tecnocientíficas ${ }^{3}$ produzidas pelo Sistema da Ciência. Assim,

3 Para fins desta pesquisa adotar-se-á o conceito de tecnociência apresentado por Dagnino (2008, p. 27) o qual ressalta que: "A ciência não consistiria de pura teoria, nem a tecnologia de pura aplicação, senão que ambas seriam integrantes de redes de cujos nós também faz parte todo tipo de instrumentos, seres e objetos relevantes à atividade que se desenvolve em seu entorno. Os produtos da atividade científica - as teorias - não poderiam então continuar sendo separados dos instrumentos - as tecnologias, inclusive - que participam da sua elaboração". De acordo Hottois, o termo tecnociência surge durante a década de 1970. E durante os anos 1980 e 1990 pode ser associado a várias conotações diferentes. Para o filósofo, inspirado em concepção bioética do termo, não há um conceito específico de tecnociência. No decurso das últimas décadas, pois, a partir do caráter instrumental da ciência, pode-se associá-la ao que é produzido e imaginado por coletivos humanos e socialmente construído. Devendo ser ressaltados os graus de dependência das ciências e das técnicas ao contexto social, político e cultural (HOTTOIS, 2001, p. 602-603). Por isso, concorda-se com Morin, pois "existe uma relação que vai da ciência à técnica, da técnica à indústria, da indústria à sociedade, da sociedade à ciência” (MORIN, 2010, p. 107). pode-se observar que o sistema do Direito pode interferir no sistema da Ciência, já que aquele apresenta uma função normativa e reguladora. No entanto, a Ciência, também pode interferir no sistema do Direito, porquanto ele precisa observar as comunicações da Ciência para decidir sobre questões ainda não regulamentadas, em especial nos casos de alta complexidade, como as ações tecnocientíficas. Eis o paradoxo!

Entretanto, estas interferências mútuas são limitadas devido à autopoiese dos Sistemas. De acordo com Luhmann $(1996,2010)$ a sociedade é composta por vários sistemas autopoiéticos, isto é, "[...] o estado no qual se encontrará o sistema após a realização de suas operações internas, a partir das limitações impostas por ele mesmo" (KREPSKY, 2015, p. 3). Todavia, embora autopoiéticos, eles precisam colocar-se em abertura com 0 meio no qual estão inseridos todos os demais sistemas (ambiente) para que ocorram evoluções sociais.

A pesquisa teve como objetivo investigar a possibilidade do Sistema do Direito colocar-se em abertura cognitiva e aprendizagem com as comunicações do Sistema da Ciência sobre ações tecnocientíficas à luz da teoria sistêmica de Niklas Luhmann. Utilizou como fonte direta de dados decisões judiciais, envolvendo novas tecnologias a fim de observar a relação entre esses dois Sistemas. Para tanto, abordar-se-á inicialmente, a complexidade social e a atuação desses dois sistemas nesse contexto de constante evolução científica. Em seguida, serão trazidas ponderações acerca de como o Direito e a Ciência se comunicam a fim de situar o aporte teórico para a análise dos dados. Na sequência será apresentada a metodologia eleita e os resultados da pesquisa.

\section{A COMPLEXIDADE DA RELAÇÃO ENTRE OS SISTEMAS JURIIDICO E CIENTÍFICO ANTE AS AÇÕES TECNOCIENTÍFICAS}

Com o avanço da ciência em um contexto de complexidade social (hipercomplexidade), no qual o Sistema da Ciência passa a gerar mais probabilidades do que certezas, o Sistema do Direito precisa decidir 
sobre demandas para as quais nem sempre estará apto. Então, surge a necessidade de observação destes dois sistemas e suas possibilidades de interação a fim de evitar danos transgeracionais que possam ocorrer em função das atividades tecnocientíficas. Destaca-se que a preocupação com as gerações vindouras, ou transgeracionais "[...] é solidária do surto de desenvolvimento da ciência moderna colocada sob o signo da acumulação progressiva de descobertas e de invenções destinadas a melhorar gradualmente a condição humana" (HOTTOIS, 2001, p. 389).

Logo, urge observar a relação da Ciência com o Direito à medida que há mudanças no sistema social global e por consequência nestes dois subsistemas parciais da sociedade. Neste cenário, a Ciência vem apresentando um crescimento acelerado, assim, o Direito, por sua vez, é instigado a ampliar o seu alcance decisório (PANNARALE, 2006, p. 9). Todavia, o Direito precisa ponderar sobre os limites de sua intervenção sobre as ações tecnocientíficas.

Por esta razão, o Sistema do Direito vem sendo questionado no que tange à instrumentalização dos processos de decisão jurídica que estejam correlacionados aos riscos e as incertezas. Até porque as consequências que podem ser geradas com a criação e uso das novas tecnologias, além de certa imprevisibilidade, podem apresentar um alcance global de seus efeitos a partir do momento em que não apresentam limites territoriais.

Assim, o poder decisório do Direito se complexifica. Primeiro porque ele não possui conhecimento sobre comunicações específicas da Ciência, já que sua atuação sistêmica é pautada em decisões/comunicações/ operações sob o código "conforme ou não conforme" o Direito. Segundo porque decidir sem tal conhecimento pode gerar riscos por não se saber as consequências que podem vir a surgir. Entretanto, paradoxalmente, não decidir sobre ações tecnocietíficas também pode ser um risco. Isso tem a ver com as limitações temporais que se apresentam ao Sistema do Direito. Diferentemente da Ciência, que ao deparar-se com a ausência de evidências concretas continuaria a pesquisar até achar provas conclusivas, o Direito deve decidir independentemente da falta dessas provas (CARVALHO, 2013, p. 126).
Para que haja uma decisão jurídica nesta seara, o Direito precisa observar as comunicações oriundas do sistema da Ciência e estar mais sujeito a irritações que advenham deste Sistema. Ou seja, embora autopoiético, e, portanto, operacionalmente fechado em seu código (direito/não direito) ele precisa se colocar em abertura cognitiva para tais comunicações, sem as quais terá dificuldades para decidir. Essa forma de ingresso das informações tecnocientíficas da Ciência no Direito se dão prioritariamente por meio de pareceres técnicos a partir do código verdade/não verdade sobre as coisas.

Aliás,

Nunca as decisões jurídicas dependeram tanto das perícias como os novos direitos. E essa dependência, paradoxalmente, significa autonomia. A decisão jurídica está obrigada a manter-se jurídica apesar da dependência em relação às informações produzidas pela perícia. (ROCHA; SIMIONI, 2012, p. 196).

Assim, apesar de utilizar as comunicações científicas como fonte informativa a fim de nortear suas decisões, o Direito deve manter sua autonomia e utilizar seu próprio código. Porque caberá ao sistema do Direito assimilar as informações científicas sob o seu código e não sob o código da Ciência, já que, ao fim e ao cabo, é o Direito quem decide sobre o que comunicou a Ciência. Afinal, ele não pode decidir com base no código verdade/não verdade, pois isso seria uma corrupção sistêmica. Nesse sentido,

[...] o papel de peritus peritorum reservado ao juiz no processo: um tal papel significa que, não obstante a variedade das verdades científicas, é ao juiz que sempre e de todo modo cabe transformar as verdades sempre falsificáveis da ciência em verdades definitivas e imutáveis para o direito. (PANNARALE, 2006, p. 15).

Isso quer dizer que a forma como o Direito vai assimilar esta comunicação depende de um acoplamento estrutural entre Direito e Ciência. Para tanto, o Direito deverá decodificá-la, isso é, fazer uma leitura a partir de sua própria estrutura e código das descrições técnicas efetuadas pelos peritos (CARVALHO, 2013, p. 122). Ademais, mediante uma seleção prévia, o sistema só irá operar ou reagir a esses estímulos se ele conseguir 
processar esses elementos ou informações na sua estrutura já existente. Afinal, para Teubner (1989, p. 174):

\begin{abstract}
Interferência não significa que a informação seja carreada entre os sistemas através de uma relação directa input-output. A informação é sempre gerada ab novo em cada subsistema social, só que, no contexto da interferência com a particularidade de ser gerada simultaneamente e na base do mesmo evento comunicativo no seio dos sistemas em causa.
\end{abstract}

É sob esse norte teórico que as decisões jurídicas foram observadas a fim de identificar-se o quão dependente das informações do Sistema da Ciência o Direito se encontra neste estágio de desenvolvimento tecnocientífico cuja incerteza é preponderante. Em um contexto em que faz com que o julgador observe não só o que há prescrito legalmente, mas, sobretudo, outras comunicações que sejam capazes de nortear suas escolhas para o futuro social.

\section{DO CENÁRIO TECNOCIENTÍFICO ÀS DECISÕES JUDICIAIS: A ESCOLHA METODOLÓGICA}

A pesquisa buscou identificar a possibilidade de abertura do Sistema do Direito por meio da absorção da comunicação do sistema da Ciência. Foi realizado um mapeamento conceitual das principais temáticas discutidas no âmbito jurídico relacionados à tecnociência.

A partir da compreensão de "tecnociência" bem como da preocupação que as ações decorrentes dela possam causar danos que sejam transgeracionais, estabeleceu-se os tipos de tecnologias que compreendem ações tecnocientíficas que têm sido levadas à decisão pelo Direito por meio do centro do sistema jurídico: os Tribunais, a partir da busca jurisprudencial nos endereços eletrônicos do Superior Tribunal de Justiça (STJ), do Tribunal Regional Federal da $4^{\mathrm{a}}$ Região (TRF4) e do Tribunal de Justiça de Santa Catarina (TJSC) no período de 01/01/2012 a 01/11/2015. As palavras-chave selecionadas para esta busca jurisprudencial foram: tecnociência, modificação genética, células tronco, clonagem, reprodução assistida, biotecnologia, milho transgênico, engenharia genética, e geneticamente modificado. Des- ta forma, chegou-se a um total de 916 acórdãos.

Em seguida foram observadas as ementas de cada acórdão para a verificação da correlação com o objetivo geral da pesquisa. Assim, chegaram-se a apenas 4 (quatro) decisões referentes às seguintes categorias: (a) Transgênico (b) Geneticamente modificado (c) Milho transgênico, sendo: 3 do Tribunal Regional Federal da $4^{\mathrm{a}}$ Região (TRF4), e 1 do Superior Tribunal de Justiça (STJ). As demais foram excluídas por não corresponderem ao objeto da pesquisa.

0 que se pode observar sumariamente a respeito da parca quantidade de decisões a respeito de novas tecnologias e ações tecnocientíficas nos Tribunais é que, embora as questões tecnológicas estejam presentes na sociedade contemporânea, apresentando um crescimento constante, não há uma demanda expressiva levada ao Judiciário para resolução de conflitos que envolvam estas questões.

Isso pode denotar que as discussões acerca das ações tecnocientíficas fiquem adstritas ao juízo de $1^{\circ}$ grau, portanto, a decisões singulares; que as ações tecnocientíficas estejam sendo autorregulamentadas apenas por institutos de pesquisa ou setores de inovação sem qualquer intervenção do Direito, ou ainda, que as demais formas de fiscalização ou regulação efetuadas por órgãos governamentais como a Comissão Técnica Nacional de Biossegurança (CTNBIO), Ministério da Ciência, Tecnologia e Inovação (MCTI) entre outras organizações tenham sido suficientes para o gerenciamento das atividades tecnocientíficas.

Considerou-se a amostra adequada para observar as escolhas argumentativas das decisões classificadas em: (a) fundamentações legais (b) princípios, e (c) pareceres técnicos, as quais são analisadas a seguir.

\section{INCERTEZA E SEGURANÇA JURIIIICA: UMA OBSERVAÇÃO SISTÊMICA A PARTIR DAS DECISÕES SOBRE AÇ̃̃ES TECNOCIENTÍFICAS}

Pode-se observar que nestas decisões o Sistema do Direito e da Ciência têm apresentando certo grau 
de comunicação. Tal interação se apresentou por meio de pareceres técnicos, que foram produzidos e apresentados ao Direito pelo sistema da Ciência a partir de seu acoplamento estrutural. Dos 4 acórdãos selecionados, $42 \%$ das argumentações dos votos pautaram-se em pareceres técnicos.

Nesse contexto, o julgado do TRF4 em agravo de instrumento no 5012993-50.2014.404.0000 trata de uma discussão interposta pela Agência Nacional do Petróleo, gás e biocombustíveis (ANP) que tem por objeto a suspensão dos efeitos decorrentes da $12^{a}$ Rodada de Licitações realizada pela ANP, que ofereceu a exploração de gás folhelho, conhecido como "gás xisto" na modalidade de fraturamento hidráulico na Bacia do Rio Paraná, em face do Ministério Público que entende que faltam conhecimentos científicos sobre os efeitos desta exploração.

Para elucidar o que vem a ser a técnica da exploração em questão, o Grupo de Trabalho Interinstitucional de Atividades de Exploração e Produção de Óleo e Gás (GTPEG) se manifestou quanto ao objeto da discussão e, segundo seu parecer técnico (perícia), há duas possibilidades de acumulação de gás natural, o gás convencional que vem a ser aquele acumulado em reservatórios de rochas tendo um alto índice de permeabilidade e o não convencional, que nada mais do que o gás aprisionado em superfícies rochosas, mas que há baixa permeabilidade, como é o casso do "folhelho", que exige técnicas adicionais para a estimulação de formação dessa rocha para a produção.

A grande preocupação quanto à técnica são efeitos oriundos desta, uma vez que segundo os pareceres técnicos, esse tipo de exploração exige uma grande quantidade de recursos hídricos, havendo em muitos casos a necessidade de se utilizar água potável, além de possíveis contaminações de aquíferos superficiais e subsuperficiais, já que estas jazidas se encontram abaixo do aquífero Guarani que vem a ser uma das maiores reservas de água potável do mundo.

Neste julgado foram encontradas 8 argumentações embasadas em pareceres técnicos das quais 7 foram sustentadas no Relatório da GTEPG e 1 na Sociedade Brasileira para o Progresso da Ciência (SBPC) juntamente com a Academia Brasileira de Ciências (ABC). Todos eles mostraram-se contrários à exploração do Gás Xisto, manifestando profunda preocupação com a inclusão dessa exploração tendo em vista a combinação de falta de conhecimento efetivo sobre as reservas brasileiras e com os riscos e danos ambientais próprios ao fraturamento.

Assim, verifica-se que o Direito considerou preponderantemente os Pareceres Técnicos deste acórdão visto que totalizaram $57 \%$ dos argumentos desta decisão. Tais Pareceres foram essenciais não só para auxiliar na decisão, mostrando dados estatísticos, mas também para conceituar o que vem a ser o objeto da controvérsia, o que é imprescindível para a decisão pelo Sistema do Direito, visto que em sua estrutura não há informação sobre tais conceitos, como se pode observar no seguinte trecho extraído da decisão:

\begin{abstract}
A partir dos relatórios técnicos contidos nos autos, particularmente do relatório do Grupo de Trabalho Interinstitucional de Atividades de Exploração e Produção de Óleo e Gás GTPEG (evento1, PROCADM15), é possível esboçar-se um breve panorama do que consiste a controvertida exploração do "gás de folhelho", também tratado como "gás de xisto", "gás não convencional", ou shale gas. (RIO GRANDE DO SUL, 2014a, on-line, grifo nosso).
\end{abstract}

Em outro julgado do mesmo Tribunal, em agravo de instrumento no 5000629-66.2012.404.7000, o objeto da discussão é a liberação de uma variedade de milho geneticamente modificado por meio de avanços nos estudos da incorporação de características de outras espécies em uma só, a fim de torná-la mais resistente ao herbicida. Este é um exemplo emblemático, pois de um lado tem-se a liberação comercial de semente geneticamente modificada em detrimento da incerteza que a sua produção e o seu consumo podem causar à natureza e ao homem.

Boa parte da celeuma está centrada no parecer técnico da CTNBio exigido pela Lei no 11.105/05 (Biossegurança), em especial na obrigação do $\S 4^{\circ}$ do artigo $14^{4}$. Ademais, o caso permite verificar

4 § 40 A decisão técnica da CTNBio deverá conter resumo de sua fundamentação técnica, explicitar as medidas de segurança e restrições ao uso do organismo geneticamente modificado (OGM) e seus derivados e considerar as particularidades das diferentes regiões do País, com o objetivo de orientar e subsidiar os órgãos e entidades de registro e fiscalização, referidos no art. 16 desta Lei, no exercício de suas atribuições. 
como elementos exclusivos do sistema da Ciência podem ser compreendidos pelo sistema do Direito e interpretados de acordo com a sua racionalidade a fim de decidir com uma margem de minimização de riscos e perigos. Este caso também evidencia como a co-evolução entre sistemas descrita por Teubner (1989) efetivamente pode ocorrer por meio da irritação das organizações que usam a via judicial para exigir do Direito uma auto-observação (decisão).

A sentença recorrida anulou a comercialização nas regiões Norte e Nordeste do Brasil por não considerar suficientes os subsídios fornecidos para garantir a particularidade dos biomas em tais regiões, bem como a sua omissão quanto ao resto das regiões do Brasil. Então, utilizou-se outra vez de Pareceres Técnicos tanto para o conhecimento do objeto em questão, quanto dos possíveis efeitos oriundos dessa nova tecnologia. Em que pese à argumentação baseada em pareceres técnicos nesta decisão tenha se limitado a 30\%, mostraram-se relevantes na medida em que o Direito não só utilizou estas perícias para dar sua decisão final como ainda discutiu sobre a falta de conhecimentos necessários para a liberação de tal espécie de milho. Nesse sentido, observa o voto do julgador nos seguintes trechos do acórdão:

\begin{abstract}
A propósito, destaque-se que ao menos dois pareceristas questionaram a ausência de estudos em áreas maiores. A esse respeito, o Dr. Manoel Xavier dos Santos estranha o fato de que o Evento de Transformação T 25 no milho tenha sido avaliado em diversos locais e anos em países de clima temperado enquanto no Brasil sua avaliação ficou restrita a poucos ambientes/ anos (fl. 585 do Anexo II). Por sua vez, o Dr. Paulo Cavalcanti Gomes Ferreira destaca que os estudos foram realizados em áreas de pequena dimensão, sendo impossível medir fluxo gênico, votando a favor da desregulamentação do milho Liberty Link condicionada à condução de um estudo de fluxo gênico a ser monitorado pela CTNBio. (RIO GRANDE DO SUL, 2014b, on-line, grifo nosso)
\end{abstract}

E ainda,

Dessa forma, reconhece-se a falha no processo no que pertine à ausência de estudos nas regiões Nor-

\begin{abstract}
te e Nordeste do país (ou mais especificamente nos biomas caatinga e amazônia), valendo destacar que, tratando-se o Brasil de país continental, com inúmeros ecossistemas e sete biomas, e sabendo-se que as condições ambientais são determinantes às avaliações de riscos, a exigência de estudos nas diversas regiões é imperativa. (RIO GRANDE DO SUL, 2014b, on-line, grifo nosso).
\end{abstract}

No que se refere à fundamentação legal, uma das categorias para selecionar os argumentos dos votos, obteve-se o resultado de 39\% das argumentações das 4 decisões da amostra. Denota-se que, embora o Direito assimile as informações de tais pareceres como forma de complemento ou direcionamento para sua decisão, estes não podem interferir (irritar sistemicamente) a ponto de tirar a autonomia do Direito, visto que se trata de um sistema autopoiético.

Nesse contexto, o julgado do TRF4 em agravo de instrumento no 5006131-93.2011.4.04.7202 (SANTA CATARINA, Tribunal Regional Federal da $4^{a}$ Região, 2015) apresenta uma temática diferente por se tratar de uma ação penal, cuja discussão preponderante é a prática de delito estipulada pelo artigo 27 da Lei no 11.105/2005 que trata de normas de segurança e mecanismos de fiscalização de atividades que envolvam organismos geneticamente modificados (OGM). Ela dispõe em seu artigo que liberar ou descartar organismos geneticamente modificados no meio ambiente, que esteja em discordância com o regulamento estabelecido pela CTNBio e pelos órgãos e entidades de registro e fiscalização sofrem pena de reclusão de um a quatro anos e multa, podendo sofrer variações agravando a pena.

Esta decisão teve $100 \%$ das argumentações do voto baseadas em fundamentação legal, mostrando novamente que primeiro o Sistema irá buscar solução em sua própria estrutura. Ou seja, havendo norma específica devidamente regulamentada com a qual ele possa fundamentar sua decisão, esta prevalecerá. 0 que não impede de colocar-se em abertura cognitiva e aprendizagem sistêmica com o Sistema da Ciência caso tal norma se mostre insuficiente para a observação do fenômeno sobre o qual deva decidir. De fato, 
neste caso, percebe-se que o Sistema do Direito em acoplamento com o Sistema da Política (legislativo) possui certa capacidade de atualização com a criação de normas a partir de novos desafios de alta complexidade apresentados pela sociedade com sua constante evolução tecnológica.

A decisão oriunda do Paraná, seguindo a mesma linha do julgado anterior no sentido de que o Direito já se manifestou e regulou tais ações, em recurso especial $n^{0} 1.220 .843$ (2010/0208180-0) do Superior Tribunal de Justiça (STJ) trata de um recurso interposto em prol da reversão de um acórdão do Tribunal Regional Federal da 4a Região o qual considerou legal a aplicabilidade da multa administrativa pelo plantio de OGM na Zona de amortecimento do Parque Nacional do Iguaçu. Na linha de raciocínio anterior, o que se verifica é que, apesar de sua abertura para o Sistema da Ciência, o Direito buscará primeiramente em sua própria estrutura os elementos estruturais e programas (legislação) para sua decisão.

Nesse sentido, o artigo 225 da Constituição Federal (CF) de 1988 é amplamente mencionado nessas decisões por se tratar de uma promessa para com o futuro. Esse compromisso é exteriorizado no texto constitucional com a previsão em seu caputde que "Todos têm direito ao meio ambiente ecologicamente equilibrado, bem de uso comum do povo e essencial à sadia qualidade de vida, impondo-se ao Poder Público e à coletividade o dever de defendê-lo e preservá- lo para as presentes e futuras gerações. "Então, no intuito de assegurar o meio ambiente saudável expressamente assegurado na CF, o sistema do Direito em acoplamento com o sistema da Política, buscou regulamentar essas ações tecnocientíficas, por meio de leis e decretos facilmente identificados na análise desta decisão conforme evidencia este trecho:

A Divisão de Fiscalização desta Superintendência deverá proceder a lavratura do competente auto de infração, tendo por fundamento legal os seguintes dispositivos: arts. $16, \S 1^{\circ}$, inc. III, 21 e 23 da Lei $n^{0}$ 11.105/2005; art. 11 da Lei n0 10.814/2003; arts. 69 70, II e V, 71, caput e inc. III do Decreto n 5.591/2005. (BRASIL, 2015, on-line).
No que tange aos princípios, outra categoria de análise de argumentos dos votos vencedores das decisões mencionados nos acórdãos que ocuparam $19 \%$, o princípio da precaução ganha um grande destaque visto que a grande preocupação com decisões, envolvendo tecnociência são os seus efeitos, sendo necessário um olhar mais cauteloso, admitindo os limites e possíveis erros humanos e a imprevisibilidade da Ciência. Nesses termos, este princípio visa proteger o meio ambiente de forma que deve ser amplamente observado pelos Estados de acordo com a suas capacidades quando houver ameaça de danos ambientais graves ou irreversíveis em que não se tenha certeza científica de seus efeitos, para que haja medidas economicamente viáveis para prevenir uma possível degradação ambiental. Assim, observa o julgador:

Diante de tecnologias novas e pouco conhecidas, que
não podem ser desprezadas em face da crescente de-
manda por energia e por bens de consumo, a melhor
atitude é aquela sugerida pelo Princípio 10 da Decla-
ração do Rio: informação, participação social e aces-
so à Justiça. (RIO GRANDE DO SUL..., 2014a, on-line,
grifo nosso).

Segundo o Relator, “Em verdade, a forma de condução da questão do fraturamento hidráulico pela ANP, antecipando a realização da licitação para o início do processo, fere o princípio da precaução, como bem assinalado pelo juízo [...]" (RIO GRANDE DO SUL, Tribunal Regional Federal da $4^{\mathrm{a}}$ Região, 2014a). Evidente neste trecho, como o Direito realiza as observações necessárias do meio e as implicações sobre as ações técnicas advindas do sistema da Ciência e como o princípio da precaução já faz parte da estrutura do Direito. Fica clara a compreensão que o jurista in casu tem sobre o que se vem argumentando até aqui.

Há que se ter a devida cautela quanto ao empoderamento dado ao homem por meio da capacidade de ação tecnológica. Nesse sentido, atribui-se ao princípio da precaução um papel significativo no que diz respeito às decisões sobre novas tecnologias, pois tem em sua aplicação a responsabilidade de evitar os riscos e danos presentes e futuros ao meio ambiente e à sociedade. 


\section{CONSIDERACÕES FINAIS}

Com a constante complexificação social e os incessantes avanços tecnológicos, o homem enquanto cidadão deve ponderar sobre os limites da intervenção humana por meio da técnica seja no próprio "ser humano" ou no ambiente em que vive. Neste contexto, sobressai-se uma operação do Direito que é a decisão, comunicação emanada pelo centro do Sistema do Direito, os Tribunais. Tais decisões podem gerar inúmeras consequências para as presentes e futuras gerações. Então, o ato de decidir, considerando que existem várias alternativas entre tantas e sempre se pode escolher uma diferente (contingência), precisa absorver o risco da seleção na medida em que, tratando-se de tecnociência, nem sempre há subsídios cognoscitivos suficientes para o Direito exercer sua função decisória caso não exista regulamentação prévia.

Afinal, ele apenas pode decidir com seu código conforme/não conforme o Direito. É por isso que ele precisa observar o que comunica o Sistema da Ciência que ingressa nas decisões por meio dos pareceres técnicos, perícias de outras áreas do saber que possuem outros códigos e que são chanceladas pelo Sistema da Ciência sob o código verdade/não verdade.

Pode-se constatar que efetivamente há uma abertura do Sistema do Direito para a comunicação do Sistema da Ciência, em especial no que tange a situações de elevada complexidade, indeterminação sobre os resultados da tecnologia e potencial efeito danoso para o homem e o ambiente incluindo danos transgeracionais que nem sempre podem ser estimados.

A partir dos argumentos dos votos das decisões selecionadas, constatou-se que quase metade deles foi pautada em perícias ou pareceres técnicos, influenciando diretamente na decisão colegiada final. Isso demonstra não só que existe a abertura e a capacidade de aprendizagem do Direito com a Ciência, bem como um acoplamento estrutural no qual se percebe uma forma indireta de delegação das decisões sobre tecnociência. Ou seja, a própria Ciência, por fim, decide sobre o que deve ou não ser realizado no âmbito tecnocientífico com a chancela da decisão jurídica.
Por outro lado e não poderia ser diferente, nos casos em que há legislação e esta não comporta dúvidas em sua aplicação, os Tribunais pautam-se essencialmente nela, deixando qualquer outro argumento em nível secundário. Ora, isso confirma o caráter sistêmico do Direito, que é fechado operacionalmente e abrindo-se cognitivamente apenas quando é preciso observar o meio, enfim, o diferente. Este tipo de argumento ocupou 39\% dos argumentos.

Embora os argumentos pautados em princípios do Direito tenha alcançado o percentual de apenas 19\% dos argumentos dos votos das decisões analisadas, quando utilizados, foram extremamente relevantes, induzindo as decisões. Logo, "fundamentação legal" e "princípios do Direito" representaram $81 \%$ dos argumentos. Como estes elementos da fundamentação pertencem à estrutura do Direito conclui-se que, embora o Direito se coloque em abertura cognitiva e aprendizagem com o Sistema da Ciência nas decisões que envolvam tecnociência e incerteza quanto as suas implicações, em última instância decisória, é o Direito, com base em sua própria estrutura que decide sobre estas questões. Todavia, a depender da temática e do grau de complexidade e especificidade da tecnologia, o Direito não pode e não consegue decidir sem a decodificação e assimilação da comunicação científica.

\section{REFERÊNCIAS}

\section{BRASIL. Constituição da República Federativa do}

Brasil, de 5 de outubro de 1988. Disponível em: <http://www.planalto.gov.br/ccivil_03/Constituicao/ Constituicao.htm>. Acesso em: 15 jul. 2016.

BRASIL. Superior Tribunal de Justiça. Recurso especial no 1.220.843. Relator: Ministro Humberto Martins. 16 abr. 2015. Disponível em: <https:// ww2.stj.jus.br/processo/revista/inteiroteor/?num registro $=201002081800 \& d t \_p u b l i c a c a 0=22 / 04 / 2015>$. Acesso em: 10 jul. 2016.

\section{CARVALHO, Délton Winter de. Dano ambiental}

futuro a responsabilização civil pelo risco

ambiental. Porto Alegre: Livraria do advogado, 2013. 
DAGNINO, Renato. Neutralidade da ciência e determinismo tecnológico. Campinas-SP: Unicamp, 2008.

HOTTOIS, Gilbert. Gerações Vindouras. In: HOTTOIS, Gilbert; MISSA, Jean-Noël. Nova enciclopédia da bioética: medicina, ambiente, biotecnologia. Lisboa: Instituto Piaget, 2001. p.389-391.

HOTTOIS, Gilbert. Tecnociência. In: HOTTOIS, Gilbert; MISSA, Jean-Noël. Nova enciclopédia da bioética: medicina, ambiente, biotecnologia. Lisboa: Instituto Piaget, 2001. p.602-606.

KREPSKY, Giselle Marie. ABERTURA DO DIREITO PARA A INOVAÇÃO E REGULAÇÃO TECNOCIENTÍFICA: Contribuições da teoria pragmático-sistêmica. In: CONPEDI/UFS. (Org.).

Direito e novas tecnologias. Florianópolis: FUNJAB, v.24, p.1-19, 2015.

LUHMANN, Niklas. La Ciencia de La Sociedad. Trad. Silvia Pappe, Brunhile Erder e Luis Felipe Segura, sob coordenação de Javier Torres Nafarrate. México: Universidad Iberoamericana; Barcelona: Anthropos, 1996.

LUHMANN, Niklas. Sistemas Sociales: Lineamentos para uma teoría general. México: Anthropos, 1998.

\section{LUHMANN, Niklas. Introdução à teoria dos}

sistemas. Tradução de Ana Cristina Arantes Nasser. 2.ed. Petrópolis: Vozes, 2010.

MORIN, Edgar. Ciência com consciência. Rio de Janeiro: Bertrand Brasil, 2010.

PANNARALE, Luigi A Ciência do Direito, conhecimento científico e decisões jurídicas: um confronto impossível. Veredas do Direito, Belo Horizonte, v.3, n.5. p.9-29, janeiro-junho de 2006.
RIO GRANDE DO SUL. Tribunal Regional Federal da 4 a Região. Agravo de instrumento no 501299350.2014.404.0000. Relator: Des. Cândido Alfredo Silva Leal Junior. 18 nov. 2014a. Disponível em: <http://jurisprudencia.trf4.jus.br/pesquisa/ inteiro_teor.php?orgao=1\&documento=6851091\&term osPesquisados=transgenico>. Acesso em: 14 jul. 2016.

RIO GRANDE DO SUL. Tribunal Regional Federal da 4a Região. Embargos de Declaração em Embargos Infringentes n' 5000629-66.2012.404.7000.

Relator: Des. Cândido Alfredo Silva Leal Junior. 04 dez. 2014b. Disponível em: <http://jurisprudencia. trf4.jus.br/pesquisa/inteiro_teor.php?orgao=1\&docu mento=6713634\&termosPesquisados=transgenico $>$. Acesso em: 26 jun. 2016.

RIO GRANDE DO SUL. Tribunal Regional Federal da 4a Região. Apelação criminal no

500613193.2011.4.04.7202. Relator: Des. João Pedro Gebran Neto. 12. Ago. 2015. Disponível em: <http:// jurisprudencia.trf4.jus.br/pesquisa/inteiro_teor.php? orgao=1\&documento $=7352363$ \&termosPesquisados $=$ geneticamente|modificado>. Acesso em: 5 jul. 2016.

ROCHA, Leonel Severo; SIMIONI, Rafael Lazzarotto. Perícias técnicas, decisões jurídicas e gestão em sistemas setoriais no contexto dos novos direitos. In: ROCHA, Leonel Severo; DUARTE, Francisco Carlos (Coord.). Direito Ambiental e Autopoiese. Curitiba: Juruá, 2012. p.193-216.

SANTA CATARINA, Tribunal Regional Federal da $4^{\mathrm{a}}$ Região, 2015

TEUBNER, Gunther. 0 direito como sistema autopoiético. Tradução de José Engrácia Antunes. Lisboa: Fundação Calouste Gulbenkian, 1989. 
1Doutoranda em Direito na Universidade do Vale do Rio dos Sinos-RS - UNISINOS; Mestre em Educação; Professora titular do Curso de Direito - FURB; Pesquisadora do Grupo de Pesquisas CNPq: Direitos Fundamentais, Cidadania e Novos Direitos, atuando nas linhas: Sistema Jurídico e Produção do Conhecimento e Bioética, Biodireito e Direitos Humanos, Departamento de Direito, Centro de Ciências Jurídicas - FURB. E-mail: gkrepsky@furb.br. Publicação com auxílio do Edital CAPES nº 002/2013 - DINTER UNISINOS/ FURB e Edital PROPEX $n^{\circ} 03 / 2015$ - FUMDES.

2 Pesquisadora de Iniciação Científica, bolsista PIBIC/FURB; Faz parte do Grupo de Pesquisas CNPq: Direitos Fundamentais, Cidadania e Novos Direitos - FURB (CNPq), atuando na linha: Sistema Jurídico e Produção do Conhecimento; Graduanda em Direito pela Universidade Regional de Blumenau - FURB, Departamento de Direito, Centro de Ciências Jurídicas FURB. E-mail: cristinethay@gmail.com 
